\title{
Baja especificidad de la taquipnea para predecir neumonía en niños de 2 a 59 meses
}

Low specificity of tachypnea to predict pneumonia in children aged 2-59 months

Hazir T y col. BMJ 2006; 333:629-635.

\section{Objetivo}

Evaluar la utilidad de la radiografía de tórax (RxTx) en menores de cinco años con neumonía no severa.

\section{Diseño}

Estudio descriptivo multicéntrico, anidado en un ensayo clínico aleatorizado y controlado sobre tratamiento antibiótico de la neumonía.

\section{Lugar}

Consultorios externos de seis hospitales de Pakistán.

\section{Pacientes}

Se analizaron las RxTx de 1848 niños de dos meses a cinco años de edad con infección del tracto respiratorio inferior y con diagnóstico de de neumonía no severa según los criterios de severidad de la neumonía de la Organización Mundial de la Salud (OMS) basados en la frecuencia respiratoria. Ver tabla 1.

Tabla 1: definición de la severidad de la neumonía según la frecuencia respiratoria.

\begin{tabular}{l|c|c}
\multicolumn{1}{c|}{ Edad } & Normal (neumonía leve) & Taqui pnea (neumonía grave) \\
\hline 2 a $\mathbf{1 2}$ meses & 25 a 40 & mayor a 50 \\
\hline 1 a $\mathbf{5}$ años & 20 a 30 & mayor a 40 \\
\hline
\end{tabular}

\section{Descripción de los tests y del test de referencia}

Se utilizó como test de referencia de neumonía el diagnostico radiológico según el acuerdo ciego de dos de tres radiólogos pediatras. El registro de la frecuencia respiratoria fue realizado en forma ciega en forma visual durante 60 segundos, con el niño despierto, en reposo, sin llanto y sin fiebre.

\section{Medición de resultado principal}

Presencia o ausencia de hallazgos radiológicos compatibles con neumonía.

\section{Resultados principales}

Se encontró evidencia radiológica de neumonía en 263 (14\%) de los niños, la mayoría con patrones insterticiales. Sólo hubo 26 con neumonías de patrón lobar. La concordancia entre los radiólogos fue moderada (kappa $=0,46)^{*}$, mientras que la duración de la enfermedad no tuvo correlación con la aparición de cambios radiológicos. No se encontraron relaciones significativas entre variables clínicas y la presencia de neumonía radiológica.

\section{Conclusiones}

Las RxTx de la mayoría de los niños con diagnostico clínico de neumonía no severa no mostraron alteraciones, lo que implica que estos niños recibirían antibióticos en forma innecesaria. La guía de la OMS debería ser revisada para ser más específica, por ejemplo con el añadido de otras variables como la fiebre, que ha demostrado identificar con mayor precisión a los pacientes que se beneficiarían con tratamiento antibiótico. A pesar de que algunos autores sostienen que la RxTx no es suficientemente sensible como para detectar neumonías en estadios tempranos (antes del tercer día) este estudio no encontró esta diferencia, ya que la incidencia de cambios radiográficos fue similar entre los niños con una evolución de su enfermedad mayor a tres días y los que fueron evaluados mas tempranamente.

Palabras claves: taquipnea, neumonía pediátrica, radiografía de tórax. Key words: tachypnea, pediatric pneumonia, chest radiography. Fuente de financiamiento: Departamento de Salud y Desarrollo del Niño y del Adolescente, OMS. Conflicto de intereses: ninguno declarado.

\section{Comentario}

La neumonía es una de las principales causas de muerte en la población menor de cinco años de los países subdesarrollados. En 1990 , la OMS propuso a la frecuencia respiratoria como elemento central para su diagnostico clínico, parámetro de sencilla medición por personal no medico en comunidades con alta mortalidad infantil (mayor a 40/1000 nacidos vivos) y de mortalidad por neumonía, nivel socioeconómico bajo y difícil acceso a un equipo radiográfico. La OMS propone iniciar tratamiento antibiótico empírico en menores de un año con una frecuencia respiratoria mayor a 50 por minuto y en menores de cinco, cuando ésta supera $40^{1}$

Si bien gracias a esta estrategia se ha logrado disminuir la tasa de mortalidad por neumonía en estos países, se ha señalado que el uso exclusivo de la frecuencia respiratoria es poco específico. EI presente trabajo, evidencia que sólo el $14 \%$ de los pacientes con diagnóstico clínico evidenciará cambios radiológicos compatibles con neumonía. Si se tiene en cuenta que algunos serán de origen viral, casi un $90 \%$ de niños con síntomas respiratorios bajos y taquipnea recibirá antibióticos en forma innecesaria. En este mismo sentido, hace unos años Swingler y col. demostraron que la realización de una RxTx a niños con taquipnea no modifica su evolución clínica².

Contar con una regla de predicción clínica desarrollada en nuestro medio que permita discriminar los niños con baja probabilidad de neumonía evitaría perdida de tiempo y recursos, e irradiación innecesaria. A pesar de que la ausencia de taquipnea es el hallazgo con mayor valor predictivo negativo para neumonía, ningún signo o síntoma puede por si solo excluir o predecir confiablemente su ausencia o presencia. Margolis propone que en un niño previamente sano con síntomas respiratorios bajos y buen estado general, la ausencia de taquipnea, de signos auscultatorios (hipoventilación y rales) y de signos de esfuerzo respiratorio (tiraje, quejido, disnea) prácticamente excluye la probabilidad de una neumonía por lo que seria innecesario realizar una $\mathrm{RxTx}^{3}$.

Deberían validarse reglas de predicción clínica sencillas, con sensibilidad y especificidad suficientes para evitar RxTx innecesarias y tratamientos empíricos injustificados.

\section{Conclusiones del Comentador}

En las zonas con acceso limitado a la RxTx se puede elegir usar la guía de la OMS guiada por la taquipnea o restringir la antibioticoterapia empírica a aquellos niños que presenten fiebre (mayor a 38 ó $38,5^{\circ} \mathrm{C}$ ) además de taquipnea.

Sebastian Fernandez [ Centro de Atención Primaria San Martín, Balcarce.]

Ver glosario*

Fernandez S. Baja especificidad de la taquipnea para predecir neumonía en menores de cinco años. Evid. Actual. Pract. Ambul. 10(1).14 Ene-Feb. 2007. Comentado de: Hazir T, Bin Nisar Y, A Qazi S y col. Chest radiography in children aged 2-59 months diagnosed with non-severe pneumonia as defined by World Health Organization: descriptive multicentre study in Pakistan. BMJ 2006; 333:629-635 PMID: 16923771. Publicación online de acceso libre: http://lbmj.com/cgi/content/full/333/7569/629

\section{Referencias}

1. BTS Guidelines for the Management of Community Acquired Pneumonia in Childhood. Thorax 2002; 57;1-24.

2. Swingler G, Hussey $G$ and Zwarenstein M. Randomised controlled trial of clinical outcome after chest radiograph in ambulatory acute lower-respiratory infection in children. The Lancet 1998;351:404-408.

3. Magolis P and Gadomski A. Does this infant have pneumonia? JAMA 1998; 279:308-13. 